\title{
Kognitivno-vedenjska obravnava samopoškodbenega vedenja v mladostništvu
}

\author{
Barbara Dolenc* \\ Zdravstveni dom Trbovlje
}

\begin{abstract}
Povzetek: Namen prispevka je predstaviti kognitivno-vedenjske strategije za obravnavo mladostnic in mladostnikov, ki se samopoškodujejo, kar je lahko v pomoč vsem, ki se v klinični praksi srečujejo s tovrstno problematiko. Samopoškodbeno vedenje je opredeljeno kot samozastrupitev ali samopoškodba in se navadno pojavi med 11. in 15. letom starosti. V obdobju mladostništva je razširjenost tovrstnega vedenja med 12 in $23 \%$, med klinično populacijo pa je pogostost takega vedenja še večja. Med najmočnejšimi napovedniki tveganja za samopoškodbeno vedenje so psihiatrične bolezni. Mladostniki pogosto poročajo tudi o občutkih kronične praznine, odtujenosti in izolacije, o brezupnosti, nemoči, neljubljenosti, nizki samopodobi in nizki frustracijski toleranci. S samopoškodbenim vedenjem so povezane predvsem težave v uravnavanju čustev ter šibke spretnosti za reševanje problemov. Če mladostniki, ki se samopoškodujejo, ne poiščejo pomoči, se lahko samopoškodbeno vedenje stopnjuje v svoji resnosti, ter hkrati predstavlja močan napovednik tveganja za samomor, zaradi česar je obravnava tovrstnega vedenja izrednega pomena. Pri obravnavi samopoškodbenega vedenja se je kognitivno-vedenjska terapija izkazala kot eden izmed učinkovitih ukrepov. Znotraj obravnave je poudarek na uravnavanju čustev, obravnavi disfunkcionalnih misli in prepričanj, okrepitvi na področju vedenjskih spretnosti (kot je reševanje problemov) ter izboljšanju medosebnih odnosov, hkrati pa poudarjamo tudi sprejemajoč, čuječ odnos do sebe in do lastne preteklosti. Raziskave kažejo, da so mladostniki po obravnavi poročali o manj pogostem samopoškodbenem vedenju in samomorilnih mislih, hkrati pa so se zmanjšali tudi simptomi depresivnosti in anksioznosti, izboljšala se je samopodoba, mladostniki so bolje uravnavali svoja čustva in težave ustrezneje reševali.
\end{abstract}

Ključne besede: samopoškodbeno vedenje, mladostništvo, kognitivno-vedenjska terapija, uravnavanje čustev, reševanje problemov

\section{Cognitive-behavioural therapy of deliberate self-harm in adolescence}

\author{
Barbara Dolenc* \\ Community Health Centre Trbovlje, Slovenia
}

\begin{abstract}
The purpose of this paper is to present cognitive-behavioural strategies for dealing with adolescents with deliberate selfharm. The presented interventions can be useful for anyone who is faced with that kind of problem in the clinical setting. Deliberate self-harm is defined as self-injury and self-poisoning. It usually occurs between the ages of 11 and 15 years. During adolescence, the prevalence of this type of behaviour is between 12 and $23 \%$. The frequency of such behaviour is even greater among the clinical population. The most powerful risk factor for deliberate self-harm is the presence of mental disorder. Adolescents often report of chronic feelings of emptiness, alienation and isolation, of hopelessness, helplessness, of being unloved, of low self-esteem and a low tolerance for stress. The increased risk of deliberate self-harm is mainly related to emotional dysregulation and poor problem solving skills. If adolescents with deliberate self-harm do not seek help, self-inflicted behaviour may increase in its severity. It also represents a strong predictor of suicide; therefore, therapeutic intervention is of utmost importance. When dealing with deliberate self-harm, cognitive-behavioural therapy has proven to be one of the effective methods of treatment. Within therapy, the emphasis is on emotion regulation, dealing with dysfunctional thoughts and beliefs, reinforcing behavioural skills (such as problem solving skills) and improving interpersonal relationships. Moreover, much attention is paid to a mindful attitude towards oneself and one's own past. Research shows that after completed treatment, adolescents reported less frequent self-harm behaviour and suicidal thoughts. At the same time, symptoms of depression and anxiety were reduced and adolescents reported of more positive self-image, better emotion regulation and better problem solving skills.
\end{abstract}

Keywords: deliberate self-harm, adolescence, cognitive-behavioural therapy, emotion regulation, problem solving

\footnotetext{
*Naslov/Address: dr. Barbara Dolenc, Zdravstveni dom Trbovlje, Rudarska cesta 12, 1420 Trbovlje, e-mail: barbara.dolenc@zd-trbovlje.si

Članek je licenciran pod pogoji Creative Commons Attribution 4.0 International licence. (CC-BY licenca).

The article is licensed under a Creative Commons Attribution 4.0 International License (CC-BY license).
} 
Namen prispevka je predstaviti kognitivno-vedenjske strategije za obravnavo mladostnic in mladostnikov ${ }^{1} \mathrm{~s}$ samopoškodbenim vedenjem, kar je lahko v pomoč vsem, ki se v klinični praksi srečujejo s tovrstno problematiko.

\section{Opredelitev pojmov}

Ko govorimo o samopoškodbenem vedenju, se zaplete že na začetku pri opredelitvi pojma. Literatura si namreč pri tem ni popolnoma skladna, saj različne definicije zajemajo različna vedenja in različno stopnjo resnosti teh vedenj. $\mathrm{V}$ smernicah angleškega nacionalnega inštituta National Institute for Health and Care Excellence (NICE, 2004) je samopoškodbeno vedenje opredeljeno kot samozastrupitev ali samopoškodba, kjer trenutni razlog za dejanje ni pomemben. To je širša definicija, kot jo navaja Svetovna zdravstvena organizacija, ki govori o dejanju, kjer izid ni smrt in pri katerem posameznik namerno izvaja nenavadno vedenje, povzroči samopoškodbe ali namerno zaužije snov, ki presega predpisan ali splošno znan terapevtski odmerek. Diagnostični in statistični priročnik za duševne bolezni DSM-5 v sekciji 3 (stanja, ki potrebujejo dodatne raziskave) loči vedenje glede na namen in opredeljuje motnjo samomorilnega vedenja in samopoškodbeno vedenje brez samomorilnih namenov (American Psychiatric Association, 2013). Ne glede na to, kako široko definicijo uporabimo, pa termin samopoškodbeno vedenje $\mathrm{v}$ obeh primerih zajema dve obliki vedenj, to je samozastrupitev ali samopoškodovanje (angl. self-injury; npr. rezanje, obešanje, sežiganje, praskanje ipd.) (Hawton, O'Connor in Saunders, 2015).

V tem prispevku bomo v termin samopoškodbeno vedenje zajeli tako vedenja brez samomorilnih teženj kot tudi vedenja z njimi, kot pojem opredeljujejo smernice NICE, prav tako pa se večina ukrepov, ki jih literatura opisuje, nanaša na obe vrsti vedenja (npr. Slee, Garnefski, Spinhoven in Arensman, 2008; Slee, Garnefski, van der Leeden, Arensman in Spinhoven, 2008).

\section{Razširjenost}

Samopoškodbeno vedenje se navadno pojavi med 11. in 15. letom starosti, zato je večina raziskav o učinkovitih oblikah pomoči narejena na vzorcu mladostnikov, le malo pa je znanega o tovrstnem vedenju pri otrocih. V zgodnjem otroštvu je pojav tega vedenja relativno redek, v poznem otroštvu pa je njegova razširjenost ocenjena med 7,5 do $8 \%$ (Hankin in Abela, 2011) in se poveča na 12 do $23 \%$ v obdobju mladostništva (Jacobson in Gould, 2007). Med klinično populacijo mladostnikov je razširjenost še višja, po nekaterih podatkih celo med 12 do $82 \%$ (Gonzales in Bergstrom, 2013). Raziskave sicer kažejo, da je začetek samopoškodbenega vedenja bolj kot od kronološke starosti odvisen od razvojne faze, to je začetka obdobja mladostništva (Hawton idr., 2015), kar naj bi bilo povezano s specifično nevrorazvojno občutljivostjo $\mathrm{v}$ tem obdobju in s povečanim tveganjem za razvoj čustvenih motenj, tveganih vedenj in občutljivostjo

\footnotetext{
${ }^{1}$ V nadaljevanju v prispevku uporabljamo zgolj moško obliko za
} mladostnike in mladostnice. za negativna mnenja drugih (Blakemore, 2008). V obdobju mladostništva je pri dekletih samopoškodbeno vedenje kar trikrat pogostejše kot pri fantih (Hawton in James, 2005; Hawton, Rodham, Evans in Weatherall, 2002; Ougrin, Tranah, Leigh, Taylor in Rosenbaum Asarnow, 2012). Samopoškodovanje je pogostejše od samozastrupljanja, pri čemer je najpogostejše vedenje rezanje (Hawton idr., 2002), čeprav se pogostost metod zelo razlikuje med različnimi kulturami (Hawton idr., 2015).

\section{Dejavniki tveganja}

Med najmočnejšimi napovedniki tveganja za samopoškodbeno vedenje so psihiatrične bolezni. Samopoškodbeno vedenje se pogosto pojavi v kontekstu depresivnega razpoloženja, anksioznosti, vedenjskih težav ali nastajajoče mejne osebnostne motnje, pogosto je $\mathrm{v}$ ozadju travmatski dogodek iz preteklosti (telesna ali spolna zloraba, nasilje v družini ipd.) (Evans, Hawton in Rodham, 2005). Izpostavljenost samopoškodbenemu vedenju v vrstniški družbi (bližnji vrstniki, ki se samopoškodujejo) prav tako predstavlja precejšen dejavnik tveganja, še posebej pri dekletih, ki se režejo (Madge idr., 2011). Prav tako je samomor $v$ družinski anamnezi pogosto povezan tako $\mathrm{z}$ večjim tveganjem za samomor mladostnika kot tudi za samopoškodovanje (Hawton idr., 2002), saj tako vedenje $\mathrm{v}$ družini daje mladostniku zgled o neustreznih in nefunkcionalnih načinih reševanja psiholoških stisk.

Mladostniki pogosto poročajo o občutkih kronične praznine, odtujenosti in izolacije (Orbach, Mikulincer, Gilboa-Schechtman in Sirota, 2003). V kontekstu opisanih neprijetnih občutkov in izkušenj poročajo tudi o brezupnosti, nemoči, občutku, da so drugim v breme, o neljubljenosti, nizki samopodobi in nizki frustracijski toleranci (Brown in Vinokur, 2003; McAuliffe idr., 2006). Šibke spretnosti za reševanje problemov naj bi bile povezane s samomorilnimi mislimi, kar spet poveča tveganje za samopoškodbeno vedenje (Townsend idr., 2001). Raziskave kažejo, da do takega vedenja pogosto pride brez premisleka, impulzivno. Lahko predstavlja reakcijo na spor s starši, konec nekega odnosa ali je posledica šolskih težav. V ozadju vedenja je pogosto povečano vzburjenje, pri čemer posameznikove misli hitro postanejo podvržene samomorilnemu mišljenju, kar poveča tveganje za samopoškodbeno vedenje (Williams, Duggan, Crane in Fennell, 2006). To še posebej drži pri tistih posameznikih z dolgo zgodovino tovrstnega vedenja. Pri slednjih je namreč vsaka naslednja epizoda samopoškodbenega vedenja sprožena z notranjimi dejavniki, kot so misel ali podoba, kar pomeni, da se vedenje lahko pojavi tudi brez zunanjih sprožilcev (Rudd, 2004). To pomeni, da vsako samopoškodbeno vedenje poveča tveganje za nadaljnja podobna vedenja in za samomor (Cooper idr., 2005, Ougrin idr., 2012).

Če mladostniki, ki se samopoškodujejo, ne poiščejo pomoči, se lahko samopoškodbeno vedenje stopnjuje v svoji resnosti, ter hkrati predstavlja močan napovednik tveganja za samomor (Asarnow idr., 2011). Raziskave kažejo, da se pri posameznikih, ki se samopoškodujejo, tveganje za zaključen samomor poviša za kar 50- do 100-krat v primerjavi s splošno populacijo (Hawton, Zahl in Weatherall, 2003). Tveganje 
za samomor ostaja visoko prvih šest mesecev po epizodi samopoškodovanja (Cooper idr., 2005), lahko pa tudi več let, če je v ozadju psihiatrična ali psihosocialna težava, ki se nadaljuje v odraslost (Harrington idr., 2005). S tega vidika je zgodnja obravnava mladostnikov, ki se samopoškodujejo, izrednega pomena.

\section{Kognitivno-vedenjski pristopi k obravnavi samopoškodbenega vedenja}

V literaturi zasledimo več različnih pristopov k obravnavi samopoškodbenega vedenja. Kot učinkovita se je izkazala dialektična vedenjska terapija (Linehan, 1993), ki je bila v osnovirazvitaza obravnavo posameznikov zmejno osebnostno motnjo, pri kateri se pogosto pojavlja tudi samopoškodbeno vedenje (Washburn idr., 2012). V skladu z osnovnimi KVT-načeli vključuje dialektična terapija trening veščin za izboljšanje medosebnih odnosov ter povečanje občutljivosti za stresne situacije, izpostavljanje in preprečevanje odziva, učenje reševanja problemov in strategije kognitivne modifikacije skupaj $\mathrm{s}$ čuječnostjo in sprejemanjem. Mladostnike se hkrati spodbuja, da razvijajo buden in neobsojajoč odnos do dogodkov, do lastnih čustev in misli. Tak čuječ pristop naj bi bil bistven za preprečevanje impulzivnega, od čustev in razpoloženja odvisnega vedenja in s tem povezanega samopoškodbenega vedenja (Slee, Arensman, Garnefski in Spinhoven, 2007). S sprejemanjem posameznike naučimo, da se mislim in čustvom ne izogibajo, kar lahko prepreči nadaljnje epizode samopoškodbenega vedenja (Williams idr., 2006). Raziskave so potrdile učinkovitost dialektične vedenjske terapije tako pri zmanjševanju resnosti kot tudi pri ponavljanju samopoškodbenega vedenja ter pri izboljšanju splošnega in socialnega funkcioniranja, ki je trajalo tudi po enem letu (Linehan idr., 2006).

Rudd je s sodelavci (2001) razvil terapijo za širši nabor pacientov s samopoškodbenim vedenjem, ne le za tiste $\mathrm{z}$ diagnosticirano mejno osebnostno motnjo. Glede na Ruddovo teorijo so $\mathrm{s}$ samopoškodbenim vedenjem povezane misli, vezane na nemoč, v ozadju pa so bazična prepričanja o neljubljenosti. Ukrepi, ki izhajajo iz te teorije, se poslužujejo predvsem restrukturacije disfunkcionalnega in distorziranega mišljenja (npr. pretirane posplošitve in dihotomne interpretacije) ter bazičnih prepričanj in hkrati učenja spretnosti, kot so asertivnost, toleranca za stres, reševanje problemov (Slee idr., 2007). Poleg tega pa Rudd poudarja tudi pomen dobrega terapevtskega odnosa, ki je lahko vir varnosti in podpore med krizami.

Berk je s sodelavci razvil kratko kognitivno terapijo za obravnavo samopoškodovalnega vedenja, ki traja deset srečanj (Berk, Henriques, Warman, Brown in Beck, 2004). $\mathrm{V}$ terapiji pacient skupaj s terapevtom naredi krizni načrt, znotraj terapije pa je poudarek na poglobljeni kognitivni konceptualizaciji iracionalnih negativnih prepričanj, ki so povezana s samopoškodbenim vedenjem. Terapevt je pri tem pristopu aktiven in bolj direktiven. Tovrstno zdravljenje učinkovito zmanjša ponavljanje samopoškodbenega vedenja, pozitivno pa vpliva tudi na razpoloženje in občutek nemoči (Berk idr., 2004; Brown in Vinokur, 2003).

\section{Možni mehanizmi sprememb v KVT samopoškodbenega vedenja}

Večina teoretičnih modelov predpostavlja, da je občutljivost za samopoškodbeno vedenje povezana s težavami v uravnavanju čustev. Mladostniki, ki se samopoškodujejo, reagirajo na stresne dogodke $\mathrm{z}$ večjim občutkom poraza in brezizhodnosti (O’Connor, 2003), hkrati pa imajo v primerjavi $\mathrm{z}$ ostalimi mladostniki manj čustvenega zavedanja, težje sprejemajo emocije in imajo več težav z nadzorom vedenja ob doživljanju negativnih čustev (Slee, Garnefski, Spinhoven in Arensman, 2008). Samopoškodbeno vedenje je s tega vidika opredeljeno kot izogibanje oziroma beg pred neprijetnimi izkušnjami. Negativna čustva so navadno najintenzivnejša tik pred samopoškodbenim vedenjem, pomembno upadejo v svoji intenzivnosti takoj za vedenjem in se spet povečajo dan po epizodi samopoškodbenega vedenja, medtem ko za pozitivna čustva velja ravno obraten vzorec (Kamphuis, Ruyling in Reijntjes, 2007). Obravnava je tako najprej usmerjena $\mathrm{v}$ spodbujanje mladostnikov, da izrazijo svoja čustva (izpostavljanje), ne da bi bili pri tem deležni različnih sodb, s čimer se v možganih zgradijo nove asociacije (Williams idr., 2006). V nadaljevanju obravnave pa mladostnike učimo spretnosti za uravnavanje čustev v situacijah, ki sprožijo samopoškodbeno vedenje, in s tem spreminjamo kognicije in vedenje, ki vplivajo na (ne)učinkovito regulacijo čustev (Slee, Spinhoven, Garnefski in Arensman, 2008). Hkrati s tem povečamo občutek in sposobnost za nadzor lastnega vedenja ob čustvenem distresu.

Nekatere teorije poudarjajo, da je višje tveganje za samopoškodbeno vedenje povezano $\mathrm{s}$ samomorilnimi mislimi, ki so pogosto glavni sprožilec tovrstnega vedenja (Slee, Garnefski, van der Leeden idr., 2008). Zato naj bi se pri obravnavi osredinili na zmanjšanje intenzivnosti specifičnih misli, vezanih na samomor, na zaznano nemoč in neljubljenost, s čimer povečamo upanje. Poleg tega se $s$ samopoškodbenim vedenjem in samomorilnimi mislimi povezujejo tudi težave na področju vedenjskih spretnosti, kot na primer na področju reševanja problemov (Slee idr., 2007). S samopoškodbenim vedenjem naj bi bilo povezano bolj pasivno in izogibalno odzivanje na težave, hkrati pa ti mladostniki težave pogosto zaznavajo kot nerešljive (McAuliffe idr., 2006), ti občutki nemoči in brezupa pa vzdržujejo težave na področju spretnosti reševanja problemov, kar poveča tveganje za samopoškodbeno vedenje. Zato naj bi bil fokus obravnave na učenju mladostnika učinkovitih strategij za reševanje problemov, kar pozitivno vpliva tudi na njegovo samopodobo (Slee idr., 2007).

Glede na nekatere teorije (npr. model občutljivost-stres, Slee, Garnefski in Spinhoven, 2008, glej tudi sliko 1) se tveganje za samopoškodbeno vedenje povečuje, kadar je posameznik s specifično občutljivostjo (npr. zgodovina travmatskih dogodkov ali določeni biološki dejavniki) soočen $\mathrm{z}$ neko stresno situacijo, ki predstavlja zunanji dejavnik. Večkrat kot se posameznik posluži samopoškodbenega vedenja pri soočanju s stresnimi situacijami, manj postaja to disfunkcionalno vedenje povezano z zunanjimi dejavniki kot takimi, ampak vedno bolj z notranjimi. To pomeni, da sčasoma lastne misli postanejo sprožilec za samopoškodbeno 


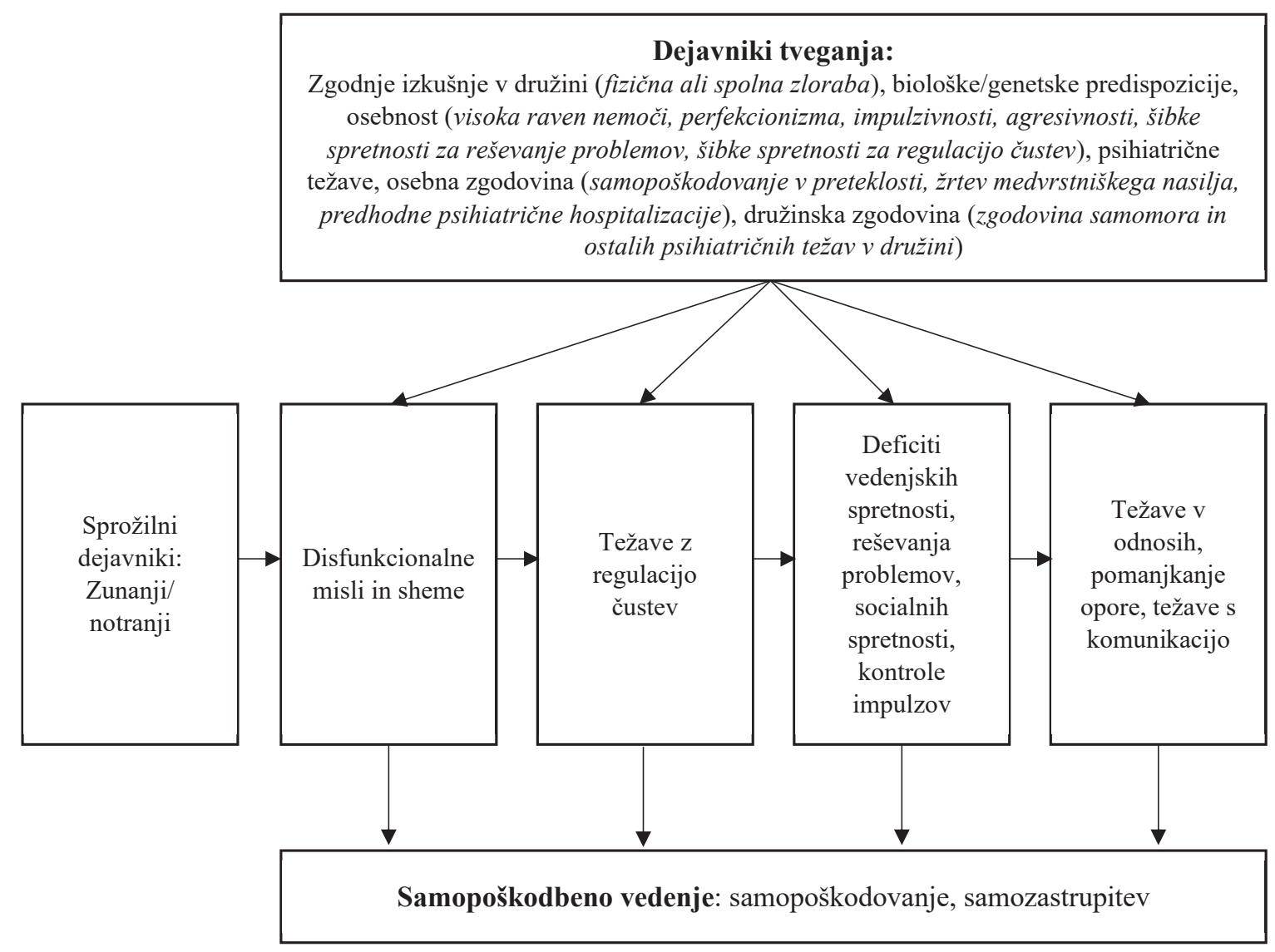

Slika 1. Teoretični model samopoškodbenega vedenja (prevedeno z dovoljenjem po Slee, Garnefski in Spinhoven, 2008).

vedenje (npr.: »Nikomur ni mar zame.«). Če povzamemo, naj bi se samopoškodbeno vedenje vzdrževalo s štirimi dejavniki, ki naj bi jih zajeli v obravnavi:

1. disfunkcionalne misli,

2. težave z uravnavanjem čustev,

3. težave pri specifičnih vedenjskih spretnostih,

4. težave z medosebnimi odnosi.

Poleg obravnave opisanih primanjkljajev pa je v obravnavi samopoškodbenega vedenja izrednega pomena tudi dober in zaupljiv terapevtski odnos, brez obsojanja mladostnikovega vedenja, ampak s ciljem razumeti njegovo vedenje v širšem kontekstu, razumeti delovanje tega vedenja in hkrati mladostnika naučiti drugačnega, funkcionalnejšega spoprijemanja s težavami (Slee idr., 2007).

\section{Učinkovitost KVT pri obravnavi samopoškodbenega vedenja}

Čeprav je raziskav o učinkovitosti posameznih terapevtskih ukrepov pri zmanjševanju samopoškodbenega vedenja malo oziroma so si nekateri rezultati celo protislovni, se je KVT izkazala kot eden izmed učinkovitih ukrepov (Brown idr., 2005; Muehlenkamp, 2006; Ougrin, Tranah, Stahl, Moran in Asarnow, 2015; Slee, Spinhoven idr., 2008). Največ dokazov o učinkovitosti glede zmanjševanja samopoškodbenega vedenja tudi pri otrocih in mladostnikih zasledimo pri dialektični vedenjski terapiji (Fleischhaker idr., 2011; Perepletchikova idr., 2011).
Raziskave kažejo, da je KVT učinkovita oblika pomoči za zmanjšanje samopoškodbenega vedenja, samomorilnih misli, simptomov depresivnosti in anksioznosti, hkrati pa pomembno izboljša samopodobo, zmožnost uravnavanja čustev in spretnost reševanja problemov (Slee, Garnefski, van der Leeden idr., 2008). To kaže, da na samopoškodbeno vedenje lahko vplivamo s spremembami v disfunkcionalnih mislih, z izboljšano zmožnostjo za uravnavanje lastnih čustev, z izboljšanjem vedenjskih spretnostih ter izboljšanjem na področju medosebnih odnosov (Slee, Garnefski in Spinhoven, 2008).

V KVT-obravnavo lahko sprejmemo vse mladostnike s samopoškodovalnim vedenjem, taka oblika obravnave pa ni najprimernejša za tiste mladostnike, katerih samopoškodovalno vedenje je posledica psihotičnega doživljanja ali pri katerih je to vedenje povezano z zlorabo alkohola in drog. Prav tako potrebujejo nekoliko drugačno obliko pomoči posamezniki z motnjami v duševnem razvoju $(\mathrm{IQ}<70)$ (Slee, Garnefski in Spinhoven, 2008).

\section{Načrt obravnave}

Ko obravnavamo samopoškodbeno vedenje, lahko uporabimo dva načina. Tovrstno vedenje obravnavamo kot simptom neke druge duševne bolezni, ki je vzrok samopoškodovanju (depresija, anksioznost ipd.). Ko obravnavamo samo bolezen, sklepamo, da bo to pozitivno vplivalo tudi na zmanjševanje samopoškodbenega vedenja. Lahko pa se v obravnavi ukvarjamo neposredno 
s samopoškodbenim vedenjem in je njegovo zmanjšanje neposredni terapevtski cilj. $\mathrm{V}$ teh primerih se $\mathrm{v}$ terapiji osredinimo na natančni pogovor o posameznih epizodah vedenja, iščemo dejavnike, ki vodijo $\mathrm{k}$ tovrstnemu vedenju, in tiste, ki ga vzdržujejo. Ta model izkoriščamo v KVT samopoškodbenega vedenja.

Obravnava samopoškodbenega vedenja je v osnovi individualna, vendar je vključevanje ostalih družinskih članov pri tem prav tako pomembno, še posebej če ti vzdržujejo tovrstno vedenje (Slee, Garnefski in Spinhoven, 2008). Med obravnavo se tudi družina nauči, kako biti do mladostnika dovolj pozoren in na kakšen način ter kako pokazati empatijo, kako spodbujati zaželena vedenja in ignorirati nezaželena. Če se mladostniki naučijo govoriti o svojih čustvih, tudi starši dobijo prostor za izražanje lastnih skrbi.

$\mathrm{V}$ nadaljevanju podrobneje predstavljamo posamezne faze terapevtskega procesa in možne ukrepe (glej tudi sliko 2). Med celotno obravnavo je nujno imeti v mislih, da so si mladostniki, ki se samopoškodujejo, med seboj zelo raznoliki po številnih lastnosti, od zgodovine preteklih samopoškodbenih vedenj, motivov za vedenje ter po psiholoških in psihiatričnih težavah (Slee idr., 2007). Zato je nujno, da se pri uporabi psihoterapevtskih ukrepov prilagajamo posamezniku in njegovim potrebam, zato predstavljeni načrt ni absolutno merilo. Bralec si lahko več o posameznih tehnikah in strategijah pri obravnavi posamezne težave (regulacija čustev, tehnike reševanja problemov ipd.) prebere v za to namenjenih učbenikih. Če se med obravnavo izkaže, da ima mladostnik samomorilne predstave ali celo namere, je treba protokol zastaviti drugače, saj je morebiti potrebna tudi hospitalizacija, vendar ta tematika presega namen tega prispevka.

\section{Formulacija primera}

V prvi fazi terapevtskega procesa je naloga terapevta, da skupaj z mladostnikom razume funkcijo samopoškodbenega vedenja in ga umesti v širši kontekst (Slee idr., 2007). Spodbudi in pomaga mladostniku, da »pove svojo zgodbo«, mu da možnost, da izrazi svoja občutja in se ob tem počuti slišanega, kar pospeši njegovo samorazumevanje in pozitivno vpliva na terapevtski odnos. V formulacijo primera je treba zajeti vse mehanizme, ki sprožijo in vzdržujejo nefunkcionalno vedenje, ter hkrati prepoznati vse varovalne dejavnike, ki jih lahko v terapiji izkoristimo. To pomeni, da moramo pridobiti dobro in podrobno anamnezo o zgodovini mladostnika, kar nam pomaga pri razumevanju, kako so pretekle izkušnje vplivale na trenutne misli, čustva, vedenjske vzorce in odnose. Tako bomo tudi lažje izbrali ustrezne ukrepe. Nadalje mladostnika prosimo, da nam opiše najbolj svežo epizodo samopoškodbenega vedenja in vse okoliščine dogodka, to je motive in razloge, saj so ti lahko od mladostnika do mladostnika različni. Nekateri se tako spoprijemajo z nevzdržnim stresom in lahko samopoškodovanje predstavlja način sproščanja tesnobe zaradi preplavljenosti z njo, lahko pa s samopoškodbenim vedenjem in občutki ob tem polnijo praznino, ki jo sicer občutijo. To je tudi način komuniciranja z drugimi, z željo ali namero vplivanja na odnos ali vedenje drugih ljudi (npr. tako prepričati drugega, da si premisli ipd.) (Hawton idr., 2015; Lloyd-Richardson, Perrine, Dierker in Kelley, 2007). Obstajajo razlike med mladostniki, ki se samopoškodujejo (npr. z rezanjem), in tistimi, ki se predozirajo, saj prvi večkrat poročajo, da je njihovo vedenje povezano z željo po zmanjšanju napetosti ali s samokaznovanjem (Rodham, Hawton in Evans, 2004).

Čeprav je torej tako vedenje pogosto posledica stiske in stresa ali neustreznih veščin, je samopoškodovanje pri mladostnikih pogosto znak za druge pomembne težave, kot je zloraba drog, nizek šolski uspeh in učne težave, odsotnost od pouka, nezaščiteni spolni odnosi, pa tudi medvrstniško nasilje ali nasilje v družini, spolna ali telesa zloraba (King idr., 2001). V intervjuju torej skušamo pridobiti čim več podatkov, ki nam bodo pomagali pri formulaciji primera, pri tem pa so pomemben vir informacij tudi mladostnikovi starši. Pomembno je pridobiti naslednje (povzeto po Washburn idr., 2012):

- opis in razumevanje trenutnih in preteklih samopoškodovalnih vedenj (tipi, metode, lokacije na telesu, pogostost, starost ob začetku samopoškodovanja, resnost izbrane metode, trenutna potreba po samopoškodovanju). Mladostnika vprašamo po pomembnih podrobnostih zadnje epizode ali tiste, ki se je najbolj spomni. Treba je vprašati o:

- dogodkih pred samopoškodbenim vedenjem,

- okoliščinah (če je bil mladostnik sam, če kdo drug od njegovih bližnjih ve za njegovo vedenje),

- resnosti izbrane metode in mladostnikovem pogledu na to,

- mislih in čustvih pred samopoškodbenim vedenjem,

- mislih in čustvih po samopoškodbenem vedenj,

- reakcijah drugih na njegovo vedenje,

- drugih posledicah (morebitne poškodbe ipd.);

opis biopsihosocialnih tveganj;

opis varovalnih dejavnikov;

oceno samomorilne ogroženosti;

oceno morebitnih pridruženih motenj (še posebej depresije, zlorabe substanc, motenj hranjenja, posttravmatske stresne motnje).

Pri ocenjevanju samopoškodovalnega vedenja si lahko pomagamo z nekaterimi strukturiranimi intervjuji, kot je na primer Self-Injurious Thoughts and Behaviors Interview (SITBI, Nock, Holmberg, Photos in Michel, 2007) ali The Suicide Attempt Self-Injury Interview (Linehan, Comtois, Brown, Heard n Wagner, 2006). V pomoč so nam lahko tudi nekateri samoocenjevalnimi vprašalniki, kot na primer Ottawa Self-Injury Inventory (Nixon, Levesque, Preyde, Vanderkooy in Clouties, 2015), The Deliberate Self-Harm Inventory (Gratz, 2001) ali Alexian Brothers Urge to SelfInjure Scale (Washburn, Juzwin, Styler in Aldridge, 2010). Žal za zdaj še nobena od lestvic ni prevedena v slovenščino.

Ob začetku oblikovano formulacijo med obravnavo seveda dopolnjujemo z na novo pridobljenimi informacijami.

\section{Načrt obravnave}

Obravnava je v nadaljevanju sestavljena iz treh faz. V zgodnji fazi mladostniku predstavimo formulacijo problema, skupaj raziskujemo pomembnost samopoškodbenega vedenja in skušamo razumeti širši kontekst tega vedenja. Na podlagi formulacije problema nato skupaj postavimo cilje. $\mathrm{V}$ srednji fazi je pozornost predvsem na vseh kognitivnih, 


\section{Formulacija primera:}

Prepoznavanje sprožilcev za samopoškodbeno vedenje, razumevanje, kako pretekle izkušnje vplivajo na naše misli, čustva, vedenje in medosebne odnose.

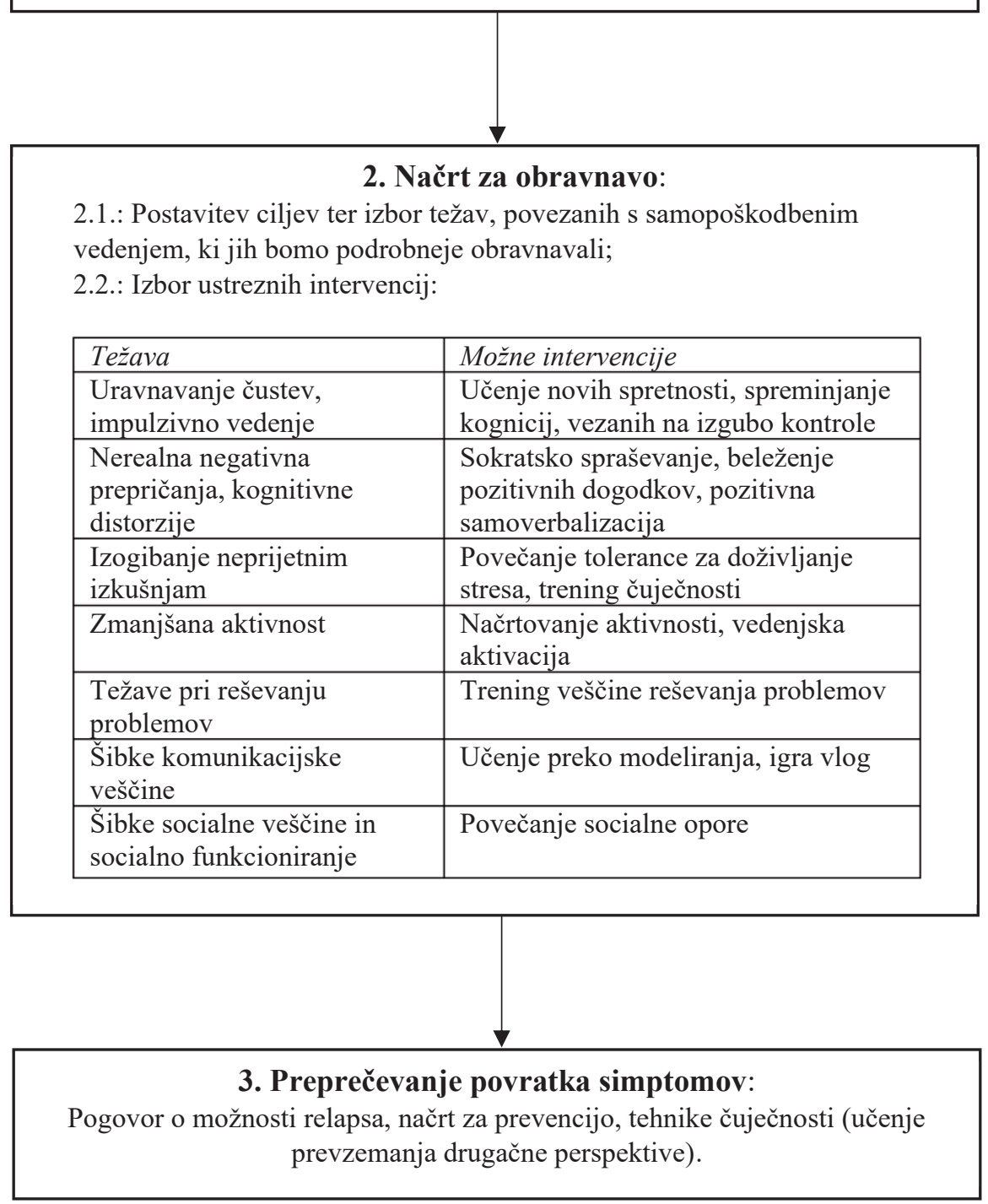

Slika 2. Diagram poteka obravnave samopoškodovalnega vedenja (povzeto po Slee idr., 2007).

čustvenih, vedenjskih in odnosnih težavah, ki vzdržujejo samopoškodbeno vedenje. $\mathrm{V}$ zadnjem delu obravnave pa se posvetimo preprečevanju ponovitve simptomov (Slee, Garnefski in Spinhoven, 2008) (glej tudi sliko 3).

\section{Začetni del obravnave}

V začetnem delu je poglavitnega pomena, da mladostniku razložimo obravnavo ter mu razumljivo predstavimo problem, da bo tudi sam razumel naravo samopoškodbenega vedenja. Razložimo mu, kako so misli, čustva, vedenje in odzivi povezani in vzdržujejo samopoškodbeno vedenje. Na podlagi funkcionalne analize vedenja skupaj z njim oblikujemo cilje obravnave, ki naj bodo vezani na dejavnike, ki vzdržujejo samopoškodbeno vedenje (Slee, Garnefski in Spinhoven, 2008). Skupaj z mladostnikom naredimo varnostni načrt, v katerem so oblikovana vedenja, ki se jih ob napetosti posluži namesto disfunkcionalnega samopoškodovanja. Prav tako z mladostnikom ne sklenemo pakta, v katerem $\mathrm{mu}$ prepovedujemo samopoškodbeno vedenje, ampak raje poudarimo, katera vedenja naj uporabi namesto neželenih (Rudd idr., 2001), morebitna samopoškodovalna vedenja in željo po njih pa obravnavamo. Ob samomorilnih predstavah moramo varovalni načrt prilagoditi.

\section{Osrednji del obravnave}

Osrednji del obravnave je namenjen dejavnikom, ki vzdržujejo samopoškodbeno vedenje, težavam na področju disfunkcionalnih misli, uravnavanja čustev, vedenjskih spretnosti in medosebnih težav.

$\mathrm{V}$ vsaki naslednji seansi vprašamo pacienta o počutju 


\begin{tabular}{|c|c|c|}
\hline Začetni del obravnave & Osrednji del obravnave & Zadnji del obravnave \\
\hline $\begin{array}{l}\text { - Psihoedukacija. } \\
\text { - Razumevanje } \\
\text { pomembnosti in } \\
\text { funkcije } \\
\text { samopoškodbenega } \\
\text { vedenja za } \\
\text { mladostnika. } \\
\text { - Racionala obravnave. } \\
\text { - Dogovori glede } \\
\text { obravnave. } \\
\text { - Formulacija ciljev. } \\
\text { - Oblikovanje } \\
\text { varnostnega načrta. }\end{array}$ & $\begin{array}{c}\text { - Ocena trenutnega razpoloženja. } \\
\text { - Ocena samopoškodbenega in/ali } \\
\text { suicidalnega vedenja v zadnjem tednu. } \\
\text { - Ocena aktualnih težav. } \\
\text { - Ocena uporabnosti varnostnega načrta. } \\
\text { - Prepoznavanje disfunkcionalnih misli, } \\
\text { težav z uravnavanjem čustev, } \\
\text { vedenjskih spretnosti, težav v odnosih } \\
\text { in intervencije, ki naslavljajo te } \\
\text { težave. } \\
\text { - Po potrebi vključitev staršev (še } \\
\text { posebej, če odnos z njimi vzdržuje } \\
\text { nefunkcionalno vedenje). }\end{array}$ & $\begin{array}{c}\text { - Utrjevanje } \\
\text { terapevtskih } \\
\text { sprememb. } \\
\text { - Preprečevanje } \\
\text { povratka simptomov. } \\
\text { - Pregled, kateri } \\
\text { elementi obravnave } \\
\text { so bili za } \\
\text { mladostnika najbolj } \\
\text { uporabni. }\end{array}$ \\
\hline
\end{tabular}

Slika 3. Kratek pregled načrta obravnave samopoškodbenega vedenja in ključnih ciljev v posameznem delu.

v zadnjem tednu, o občutkih napetosti, žalosti, o mislih na samopoškodbeno vedenje in samomor. Tako pomagamo mladostniku, da postane pozoren na svoja čustva in pomembne misli in jih izrazi. Nadalje povprašamo o številu epizod samopoškodbenega vedenja v zadnjem tednu, o čemer se tudi podrobneje pogovorimo.

$\mathrm{Z}$ mladostnikom se lahko dogovorimo, da si vse epizode samopoškodbenega vedenja ali situacije, ko je bila želja za to izredno močna, zapišejo, kar nam omogoča vpogled $\mathrm{v}$ kognicije, čustva, vedenja in odnosne težave, ki jih lahko obravnavamo na seansah. Primer tabele, kamor si mladostniki lahko zapisujejo okoliščine samopoškodbenega vedenja, je na sliki 4.

Tovrstno beleženje nam omogoča vpogled v interpretacijo dogodka in disfunkcionalnega vedenja, $v$ intenziteto njegovih čustev in načine, kako se mladostnik s tem spoprijema. Po določenem času navadno beleženje tovrstnih dogodkov razkrije občutke strahu pred zapustitvijo (Slee, Garnefski in Spinhoven, 2008), lahko pa tudi specifične težave $z$ uravnavanjem čustev ali na področju vedenjskih spretnosti. V nadaljevanju predstavljamonekaj možnih tehnik za posamezne težave na področju misli, čustev, vedenja ali medosebnih odnosov. Pomembno je, da pri izboru strategij nismo rigidni in jih prilagodimo vsakemu posamezniku. Predstavljenih je le nekaj možnosti, več o posameznih tehnikah in strategijah si lahko bralec prebere v za to namenjenih učbenikih.
Obravnava težav na področju misli:

- Prepoznavanje disfunkcionalnih in samomorilnih misli: Mladostniki, ki se samopoškodujejo, o sebi, drugih in svetu razmišljajo bolj negativno (Slee, Garnefski, Spinhoven in Arensman, 2008). Te misli lahko nihajo od blage samokritičnosti (»Žalost je znak šibkosti.«) do samomorilnih misli (»Svet bo lepši brez mene.«). Prav tako imajo pogosto izkrivljene misli, vezane na samopoškodbeno vedenje, ki oslabijo njihovo motivacijo za spremembo (»Želja po samopoškodovanju je prevelika, da bi jo lahko nadzoroval.«). Samomorilne misli zahtevajo posebno pozornost, še posebej tiste, ki se nanašajo na občutek, da mladostnik drugim predstavlja breme, misli o nemoči, o nevrednosti biti ljubljen in misli, da so občutena čustva nevzdržna. Te misli imajo skupno to, da spodbudijo občutek brezupa in so pomembni sprožilci samopoškodbenega in samomorilnega vedenja (Rudd idr., 2001; Slee, Garnefski in Spinhoven, 2008). Med obravnavo se mladostniki naučijo prepoznati te misli, kritično razmišljati o njihovi realnosti in koristnosti ter zavzeti distanco od njih.

- Kognitivna restrukturacija: Ta zavzema ne le prepoznavanje negativnih misli, ampak tudi kritično oceno njihove realnosti in koristnosti ter poskus distanciranja od njih. Dnevnik situacij, ki so sprožile samopoškodbeno vedenje, nam omogoča uvid v povezavo med negativnimi

\begin{tabular}{|l|l|l|l|l|}
\hline Datum & Situacija & $\begin{array}{l}\text { Misli } \\
\text { (kaj mi je šlo v } \\
\text { tistem trenutku } \\
\text { skozi misli?) }\end{array}$ & $\begin{array}{l}\text { Čustva } \\
\text { (Kaj sem v tistem hipu } \\
\text { čutil?) } \\
\text { [intenzivnost 0-100] }\end{array}$ & $\begin{array}{l}\text { Vedenje } \\
\text { (kaj sem za tem } \\
\text { naredil?) }\end{array}$ \\
\hline 24. avgust & $\begin{array}{l}\text { Starši mi niso } \\
\text { dovolili, da grem } \\
\text { sfantom v kino. }\end{array}$ & $\begin{array}{l}\text { Nikoli mi ničesar } \\
\text { ne pustijo. } \\
\text { Nimajo me radi. }\end{array}$ & $\begin{array}{l}\text { jeza [80] } \\
\text { žalost [50] }\end{array}$ & $\begin{array}{l}\text { Kričanje. } \\
\text { Praskanje. } \\
\text { Rezanje. }\end{array}$ \\
\hline
\end{tabular}

Slika 4. Primer zapisa okoliščin samopoškodbenega vedenja. 
mislimi in negativnimi čustvi, prav tako nam da uvid v specifično vsebino teh misli. Med obravnavo učimo mladostnika kritičnosti do teh misli, tako da išče dokaze in protidokaze za to misel ter oblikuje alternativne, realnejše in koristnejše misli ter s tem zavzame drugo perspektivo.

- Prepoznavanje disfunkcionalnih shem: $\mathrm{Ob}$ tem, ko se podrobneje ukvarjamo $\mathrm{z}$ vsebino disfunkcionalnih in samomorilnih misli, dobimo boljši uvid v disfunkcionalne sheme, pravila in predpostavke ter bazična prepričanja, ki ležijo v ozadju. Pri prepoznavanju shem si pomagamo s tehniko sokratskega spraševanja, z metaforami, z uporabo ekstremnih primerjav ipd.

- Vedenjski eksperiment: Z uporabo vedenjskega eksperimenta lahko prav tako naslovimo in kritično ovrednotimo realnost misli in prepričanj. Vedenjski eksperiment vedno oblikujemo individualno glede na specifične težave posameznika.

Obravnava težav na področju čustev:

- Opazovanje čustev: Nekateri mladostniki, ki se samopoškodujejo, poročajo o tem, da ničesar več ne občutijo, pri čemer ima samopoškodbeno vedenje funkcijo polnjenja praznine (Hawton idr., 2015; Lloyd-Richardson idr., 2007). Pomembno je identificirati vzroke, zakaj se mladostnik ob lastnih čustvih počuti tako ogroženo. Lahko se boji, da bi ob čustvovanju postal $\mathrm{z}$ njim popolnoma preplavljen in je to tudi oblika samozaščite. Če mladostnika učimo opazovanja lastnih čustev, lahko pri sebi prepozna, da se lastnim čustvom izogiba. Ta uvid je lahko začetek obravnave izogibanja. Pomembno je, da do tega prihajamo postopoma, da se izognemo morebitnemu preplavljenju.

- Izkustvene vaje: Kadar se mladostniki bojijo lastnih čustev, ta strah lahko dodatno okrepi intenziteto čustev. Za obravnavo izogibanja lastnim čustvom lahko uporabimo izkustvene vaje, da preverimo ali izzovemo katastrofične misli o lastnih čustvih. Tako mladostnik do čustev zavzame drugačen pogled, da se čustva lahko spreminjajo in da jih lahko zdrži. Mladostnik, ki se samopoškoduje, se navadno niti ne zaveda, da se lahko celo najbolj intenzivna čustva zmanjšajo $v$ svoji intenziteti, saj ne zmore počakati do trenutka, ko čustva spontano začnejo izzvenevati, saj se do takrat že pojavi samopoškodbeno vedenje. Ena od pomembnih izkušenj za mladostnike je tudi ta, da je doživljanje čustev pomembno in vredno človeško doživljanje.

- Tehnike čuječnosti: Osredinjajo se na senzorično zavedanje $\mathrm{v}$ trenutku, brez sojenja, ali je nekaj prijetno ali neprijetno. Povečana pozornost na tukaj in zdaj, kar vaje čuječnosti zahtevajo, pomaga pri zmanjševanju impulzivnega vedenja.

- Učenje prepoznavanja čustev: Mladostniki pogosto prepoznajo čustva šele takrat, ko postanejo ta zelo intenzivna, kar poveča tveganje za samopoškodbeno vedenje $\mathrm{z}$ namenom ustaviti boleče doživljanje. Mladostnike učimo prepoznavanja tudi manj intenzivnih čustev in s tem ukrepanja, preden le-ta postanejo tako intenzivna, da so za njih nevzdržna.

- Učenje razlikovanja in poimenovanja čustev: Pogosto mladostniki, ki se samopoškodujejo, poznajo le dve kategoriji čustev in ta dihotomno razvrščajo (npr. v prijetna in neprijetna) (Slee, Garnefski in Spinhoven, 2008). Takšno dihotomno zaznavanje vpliva na to, da mladostniki težje uvidijo vpliv misli na lastna čustva in posledično tudi težje razumejo pomen kognitivnih ukrepov. Mladostnika spodbujamo, da opazuje svoje telesne senzacije in spremljajoča čustva in mu pomagamo, da svoja doživljanja in izkušnje ubesedi.

- Uravnavanje intenzivnih čustev: Nekateri mladostniki se čustev izogibajo, drugi ne zdržijo, da v čustvenem doživljanju ostanejo predolgo. Pomagamo jim, da se naučijo tehnik samotolažbe, lahko tudi s pomočjo preusmerjanja pozornosti na druge aktivnosti.

Obravnava težav na področju vedenja:

- Opazovanje težav in postavljanje prednostnih nalog: Mladostniki, ki se samopoškodujejo, v splošnem doživljajo več stresnih dogodkov in imajo nižjo frustracijsko toleranco (Brown in Vinokur, 2003; McAuliffe idr., 2006). Prav tako na težave reagirajo bolj pasivno in se reševanju le-teh pogosto izogibajo, kar povzroči kopičenje več in več težav in posledično večje tveganje za pojav samopoškodbenega vedenja. Kadar mladostniki poročajo o številnih težavah, je treba oblikovati prednostne naloge in najprej obravnavati tiste težave, ki so najbolj povezane s samopoškodbenim vedenjem.

- Spodbujanjeuporabefunkcionalnihspretnostizareševanje problemov, ki jih mladostnik že obvlada: Mladostniku pomagamo prepoznati ustrezne in funkcionalne strategije, ki jih v življenju že obvlada. S prepoznavanjem njim že znanih in učinkovitih strategij lahko zbudimo občutek nadzora nad situacijo. Ob hkratnem učenju in razvijanju novih strategij se spretnosti reševanja problemov med obravnavo lahko pomembno izboljšajo in pozitivno vplivajo tako na mladostnikovo samopodobo kot tudi na občutek večjega nadzora, s čimer se zmanjša težnja po samopoškodovanju (Slee, Garnefski, van der Leeden idr., 2008).

- Vzpostavljanje stopenjskega načrta za reševanje težav: Mladostniki v začetku pogosto poročajo o tem, da so s težavami preplavljeni, da verjamejo, da so te zanje nerešljive, kar predstavlja pomemben povod za neustrezna vedenja, kot je samopoškodovanje (Slee, Garnefski, van der Leeden idr., 2008). Mladostnike učimo tehnike reševanja problemov, pri katerih naj se s težavami spoprimejo korak za korakom. Najprej težavo ubesedijo, nato iščejo možne rešitve (možganska nevihta), izberejo rešitev, jo uporabijo $\mathrm{v}$ praksi in jo na koncu vrednotijo.

- Zmanjšanje nefunkcionalnih vedenj, ki povečajo možnost za samopoškodbeno vedenje: Na primer, nošnja britvic, nožev s seboj, zloraba alkohola in drog, druženje $\mathrm{z}$ vrstniki, ki se samopoškodujejo (tudi vključitve v skupine na socialnih omrežjih, ki spodbujajo tovrstna vedenja), izpostavljanje ljudem, ki zastrašujejo ali ponižujejo druge ipd.

- Sprejemanje okoliščin, ki jih ne moremo spremeniti: V nekaterih primerih je sprejemanje edina možna rešitev.

- Vedenjska aktivacija: Povečanje pogostosti prijetnih aktivnosti v vsakdanu je lahko za mladostnika zelo spodbudno in pozitivno vpliva na njegovo razpoloženje. 
Obravnava težav na področju medosebnih odnosov:

- Izboljšanje veščine komunikacije: Med iskanjem pomoči je komunikacija med mladostnikom in družino ali prijatelji pogosto neustrezna. Znotraj obravnave je poudarek na asertivnosti (uporaba jaz-stavkov, ustrezno in neagresivno izražanje lastnih misli, čustev in potreb), aktivnem poslušanju (učenje pozornega poslušanja misli, čustev in potreb drugih brez obsojanja ali neverbalnih sodb, kot je na primer zavijanje $z$ očmi) in ustreznem odzivanju na druge (spodbujanje empatije, postavljanje v vlogo drugega družinskega člana, učenje reflektiranja svojega razumevanja do čustev in misli drugega). Tehnike ustrezne komunikacije pogosto vadimo na obravnavah skupaj z ostalimi družinskimi člani.

- Povečanje socialne opore: Mladostniku pomagamo, da si ustvari večjo socialno mrežo, ki naj bo sestavljena tako iz prijateljev in družine kot tudi šolskega osebja in drugih pomembnih ljudi. Če ima mladostnik težave pri tem, da prosi druge za pomoč, je pomembno, da skušamo obravnavati vprašanje, kaj ga pri tem ovira, kakšne misli in občutki so v ozadju (lahko so misli nemoči ali nezaupanja ali občutki sramu).

- Vzpostavljanje varnega in zaupnega terapevtskega odnosa: Pomembno je, da kot terapevti izražamo empatijo in mladostnikovih dejanj ne sodimo. Terapevtski odnos je eden od najučinkovitejših opor (Slee, Garnefski in Spinhoven, 2008). Izražanje topline, zanimanja in skrbi omogoči terapevtu, da podkrepi zaželeno vedenje. Vzdrževanje jasnih mej je prav tako učinkovito pri zmanjševanju neželenih vedenj, hkrati pa omejitve dajo občutek organiziranosti v življenje mladostnika in jasno sliko, katero vedenje je sprejemljivo in katero ne.

\section{Zadnji del obravnave: Preprečevanje povratka simptomov}

V sklepnih fazah obravnave je poudarek na preprečevanju povratka simptomov (Slee, Garnefski in Spinhoven, 2008). Skupaj z mladostnikom ob vsem védenju o sprožilcih nefunkcionalnega vedenja iščemo prihodnje rešitve, ki zmanjšajo tveganje za povratek simptomov. Mladostniku pomagamo, da si predstavlja te situacije (lahko z uporabo tehnike imaginacije), in skupaj preigramo scenarije. Tako dobimo tudi jasnejšo sliko, ali je mladostnik dobro opremljen za ustrezno reševanje nadaljnjih težav. V sklepnem delu terapije je pomemben poudarek tudi na refleksiji obravnave. Mladostnik naj razmišlja, kaj je bilo zanj najuporabnejše. Skupaj lahko naredimo kartice $\mathrm{z}$ najučinkovitejšimi strategijami, ki so lahko v pomoč pri reševanju nadaljnjih stisk. Hkrati ga spodbudimo, da čuječe sprejme trenutno mesto in stališče do preteklih neustreznih vedenj, misli in čustev. Tak sprejemajoč odnos do lastnih čustev, misli in telesnih občutkov naj bi preprečeval morebitno napredovanje negativnih misli do samopoškodbenega vedenja in morebitne samomorilne predstave (Williams idr., 2006).

\section{Sklepi}

Obravnava samopoškodbenega vedenja je celovita, saj je tovrstno vedenje pogosto le simptom druge duševne motnje, ki je v ozadju, funkcija tega vedenja pa je od mladostnika do mladostnika pogosto različna, zato se moramo vedno prilagajati posamezniku in njegovim specifičnim težavam. Poleg tega še vedno ni popolnoma jasno, kateri so mehanizmi spremembe pri obravnavi samopoškodbenega vedenja, saj to področje še vedno ostaja precej neraziskano.

V kontekstu tega članka sem se skušala poglobiti predvsem v obravnavo samopoškodbenega vedenja kot enega izmed simptomov, medtem ko je v terapiji treba zajeti širši kontekst in obravnavati morebitno depresivno razpoloženje, aktualne stresorje in težave, povezane $\mathrm{z}$ mladostniškim razvojnim obdobjem ipd.

\section{Literatura}

American Psychiatric Association. (2013). Diagnostic and statistical manual of mental disorders, 5th ed. (DSM-5). Arlington: American Psychiatric Publishing.

Asarnow, J. R., Porta, G., Spirito, A., Emslie, G., Clarke, G., Wagner, K. D., ... in Brent, D. (2011). Suicide attempts and nonsuicidal self-injury in the treatment of resistant depression in adolescents: Findings from the TORDIA trial. Journal of the American Academy of Child and Adolescent Psychiatry, 50(8), 772-781.

Berk, M. S., Henriques, G. R., Warman, D. M., Brown, G. K. in Beck, A. T. (2004). A cognitive therapy intervention for suicide attempters: An overview of the treatment and case examples. Cognitive and Behavioral Practice, 11(3), 265-277.

Blakemore, S. J. (2008). The social brain in adolescence. Nature Reviews Neuroscience, 9(4), 267-277.

Brown, G. K., Ten Have, T., Henriques, G. R., Xie, S. X., Hollander, J. E. in Beck, A. T. (2005). Cognitive therapy for the prevention of suicide attempts. A randomized controlled trial. Journal of the American Medical Association, 294(5), 563-570.

Brown, S. L. in Vinokur, A. D. (2003). The interplay among risk factors for suicidal ideation and suicide: the role of depression, poor health, and loved ones' messages of support and criticism. American Journal of Community Psychology, 32(1-2), 131-141.

Cooper, J., Kapur, N., Webb, R., Lawlor, M., Guthrie, E., Mackway-Jones, K., Appleby, L. (2005). Suicide after deliberate self-harm: A 4-year cohort study. American Journal of Psychiatry, 162(2), 297-303.

Evans, E., Hawton, K. in Rodham, K. (2005). Suicidal phenomena and abuse in adolescents: a review of epidemiological studies. Child Abuse and Neglect, 29(1), $45-58$.

Fleischhaker, C., Böhme, R., Sixt, B., Brück, C., Schneider, C. in Schulz, E. (2011). Dialectical Behavioral Therapy for Adolescents (DBT-A): a clinical trial for patients with suicidal and self-injurious behavior and borderline symptoms with a one-year follow-up. Child and Adolescent Psychiatry and Mental Health, 5(1), 3. 
Gonzales, A. H. in Bergstrom, L. (2013). Adolescent NonSuicidal Self-Injury (NSSI) Interventions. Journal of Child and Adolescent Psychiatric Nursing, 26(2), 124-130.

Gratz, K. L. (2001). Measurement of deliberate self-harm: preliminary data on the deliberate self-harm inventory. Journal of Psychopathology and Behavioral Assessment, 23(4), 253-263.

Hankin, B. L. in Abela, J. R. (2011). Nonsuicidal self-injury in adolescence: prospective rates and risk factors in a 2(1/2) year longitudinal study. Psychiatry Research, 186(1), 65-70.

Harrington, R., Pickles, A., Aglan, A., Harrington, V., Burroughs, H. in Kerfoot, M. (2005). Early adult outcomes of adolescents who deliberately poisoned themselves. Journal of the American Academy of Child and Adolescent Psychiatry, 45(3), 337-345.

Hawton, K. in James, A. (2005). Suicide and deliberate selfharm in adolescents. British Medical Journal, 33, 891-894.

Hawton, K., O'Connor, R. C. in Saunders, K. E. A. (2015). Suicidal behavior and self-harm. V A. Thapar, D. S. Pine, Lockman, J. F., Scott, S., Snowling, M. J. in Taylor, E. (ur.), Rutter's Child and Adolescent Psychiatry, 6th ed. (str. 893-912). Chichester: John Wiley and Sons Ltd.

Hawton, K., Rodham, K., Evans, E. in Weatherall, R. (2002). Deliberate self-harm in adolescents: self report survey in schools in England. British Medical Journal, 325(7374), 1207-1211.

Hawton, K., Zahl, D. in Weatherall, R. (2003). Suicide following deliberate self-harm: long-term follow-up of patients who presented to a general hospital. British Journal of Psychiatry, 182, 537-542.

Jacobson, C. M. in Gould, M. (2007). The epidemiology and phenomenology of nonsuicidal self-injurious behavior among adolescents: a critical review of the literature. Archives of Suicide Research, 11(2), 129-147.

Kamphuis, J. H., Ruyling, S. B. in Reijntjes, A. H. (2007). Testing the emotion regulation hypothesis among selfinjuring females: Evidence for differences across mood states. The Journal of Nervous and Mental Disease, 195(11), 912-918.

King, R. A., Shwab-Stone, M., Flisher, A. J., Greenwald, S., Kramer, R. A., Goodman, S. H., ... in Gould, M. S. (2001) Psychosocial and risk behavior correlates of youth suicide attempts and suicidal ideation. Journal of the American Academy of Child and Adolescent Psychiatry, 40(7), 837-846.

Linehan, M. M. (1993). Cognitive-behavioral treatment of borderline personality disorder. New York: The Guilford Press.

Linehan, M. M., Comtois, K. A., Brown, M. Z., Heard, H. L. in Wagner, A. (2006). Suicide Attempt Self-Injury Interview (SASII): development, reliability, and validity of a scale to assess suicide attempts and intentional selfinjury. Psychological Assessment, 18(3), 303-312.
Linehan, M. M., Comtois, K. A., Murray, A. M., Brown, M. Z., Gallop, R. J., Heard, H. L., ... in Lindenboim, N. (2006). Two-year randomized controlled trial and followup of dialectical behavior therapy vs therapy by experts for suicidal behaviors and borderline personality disorder. Archives of General Psychiatry, 63(7), 757-766.

Lloyd-Richardson, E. E., Perrine, N., Dierker, L. in Kelley, M. (2007). Characteristics and functions of non-suicidal self-injury in a community sample of adolescents. Psychological Medicine, 37(8), 1183-1192.

Madge, N., Hawton, K., McMahon, E. M., Corcoran, P., De Leo, D., de Wilde, E. J., ... in Arensman, E. (2011). Psychological characteristics, stressful life events and deliberate self-harm: findings from the Child \& Adolescent Self-harm in Europe (CASE) Study. European Child and Adolescent Psychiatry, 20(19), 499-508.

McAuliffe, C., Corcoran, P., Keeley, H. S., Arensman, E., Bille-Brahe, U., De Leo, D., ... in Wasserman, D. (2006). Problem solving ability and repetition of deliberate selfharm: a multicentre study. Psychological Medicine, 36(1), 45-55.

Muehlenkamp, J. J. (2006). Empirically supported treatments and general therapy guidelines for non-suicidal selfinjury. Journal of Mental Health Counseling, 28(2), 166-185.

National Institutte for Health and Care Excellence, NICE (2004). Self-harm: The short-term physical and psychological management and secondary prevention of self-harm in primary and secondary care. Leucester (UK): The British Psychological Society.

Nixon, M. K., Levesque, C., Preye, M., Vanderkooy, J. in Clouties, P. F. (2015). The Ottawa Self-Injury Inventory: Evaluation of an assessment measure of nonsuicidal selfinjury in an inpatient sample of adolescents. Child and Adolescent Psychiatry and Mental Health, 9, 26.

Nock, M. K., Holmberg, E. B., Photos, V. I. in Michel, B. D. (2007). Self-injurious thoughts and behaviors interview: development, reliability, and validity in an adolescent sample. Psychological Assessment, 19(3), 309-317.

O'Connor, R. C. (2003). Suicidal behavior as a cry of pain: Test of a psychological model. Archives of Suicide Research, 7(4), 297-308.

Orbach, I., Mikulincer, M., Gilboa-Schechtman, E. in Sirota, P. (2003). Mental pain and its relationship to suicidality and life meaning. Suicide \& Life-Threatening Behavior, 33(3), 231-241.

Ougrin, D., Tranah, T., Leigh, E., Taylor, L. in Asarnow, J. R. (2012). Practitioner Review: Self-harm in adolescents. Journal of Child Psychology and Psychiatry, 53(4), $337-350$.

Ougrin, D., Tranah, T., Stahl, D., Moran, P. in Asarnow, J. R. (2015). Therapeutic Interventions for Suicide Attempts and Self-Harm in Adolescents: Systematic Review and Meta-Analysis. Journal of the American Academy of Child and Adolescent Psychiatry, 54(2), 97-107. 
Perepletchikova, F., Axelrod, S. R., Kaufman, J., Rounsaville, B. J., Douglas-Palumberi, H. in Miller, A. L. (2011). Adapting dialectical behaviour therapy for children: towards a new research agenda for paediatric suicidal and non-suicidal self-injurious behaviours. Child and Adolescent Mental Health, 16(2), 116-121.

Rodham, K., Hawton, K. in Evans, E. (2004). Reasons for deliberate self-harm: comparison of self-poisoners and self-cutters in a community sample of adolescents. Journal of the American Academy of Child and Adolescent Psychiatry, 43(1), 80-87.

Rudd, M. D. (2004). Cognitive therapy for suicidality: An integrative, comprehensive, and practical approach to conceptualization. Journal of Contemporary Psychotherapy, 34(1), 59-72.

Rudd, M. D., Joiner, T. in Rajab, M. H. (2001). Treating suicidal behaviour. An effective, timelimited approach. New York: The Guilford Press.

Slee, N., Arensman, E., Garnefski, N. in Spinhoven, P. (2007). Cognitive-behavioral therapy for deliberate self-harm. Crisis, 28(4), 175-182.

Slee, N., Garnefski, N. in Spinhoven, P. (2008). Treatment Protocol for deliberate self-harm in adolescents and adults. V N. Slee (ur.), Cognitive-behavioural therapy for deliberate self-harm (str. 31-53). Enschede: PrintPartners Ipskamp.

Slee, N., Garnefski, N., Spinhoven, P. in Arensman, E. (2008). The influence of cognitive emotion regulation strategies and depression severity on deliberate self-harm. Suicide and Life-Threatening Behavior, 28(3), 274-286.

Slee, N., Garnefski, N., van der Leeden, R., Arensman, E. in Spinhoven, P. (2008). Cognitive-behavioural intervention for self-harm: randomised controlled trial. The British Journal of Psychiatry, 192(3), 202-211.

Slee, N., Spinhoven, P., Garnefski, N. in Arensman, E. (2008). Emotion regulation as mediator of treatment outcome in therapy for deliberate self-harm. Clinical Psychology and Psychotherapy, 15(4), 205-216.

Townsend, E., Hawton, K., Altman, D. G., Arensman, E., Gunnell, D., Hazell, P., ... in Van Heerugen, K. (2001). The efficacy of problem solving treatments after deliberate self-harm: metaanalysis of randomized controlled trials with respect to depression, hopelessness and improvement in problems. Psychological Medicine, 31(6), 979-988.

Washburn, J. J., Juzwin, K. R., Styer, D. M. in Aldridge, D. (2010). Measuring the urge to self-injure: preliminary data from a clinical sample. Psychiatry Research, 178(3), 540-544.

Washburn, J., Richardt, S. L., Styer, D. M., Gebhardt, M., Juzwin, K. R., Yourek, A. in Aldridge, D. (2012). Psychotherapeutic approaches to non-suicidal self-injury in adolescents. Child and Adolescent Psychiatry and Mental Health, 6, 14.

Williams, J. M. G., Duggan, D. S., Crane, C. in Fennell, M. J. V. (2006). Mindfulness-based cognitive therapy for prevention of recurrence of suicidal behavior. Journal of Clinical Psychology, 62(2), 201-210. 